\title{
Toxicity and bacterial anti-motility activities of the hydroethanolic extract of Acacia senegal (L.) Willd (Fabaceae) leaves
}

René Dofini Magnini ${ }^{1,2,3^{*}}$ (D), Mathieu Nitiéma², Geoffroy G. Ouédraogo ${ }^{2}$, Sylvain llboudo ${ }^{2,4}$, Alimata Bancé ${ }^{2,3}$, Hassanata Millogo-Koné ${ }^{2}$, Carole Di Giorgio ${ }^{5}$, Jean-Marie Pagès ${ }^{1}$, Adama Hilou ${ }^{3}$ and Anne Davin-Regli ${ }^{1}$

\begin{abstract}
Background: Acacia senegal is a plant traditionally used for its various properties, including the treatment of infectious diseases. Recently, our team has demonstrated the ability of the hydroethanolic extract of the leaves to increase the activity of phenicol antibiotics against multi-resistant bacteria. The aim of this work is to determine the toxicological effects of the extract and its capacity to inhibit the bacterial mobility of Gram-negative bacteria, in order to evaluate the level of safety use of this plant.

Methods: The cytotoxicity test was performed using the neutral red absorption method. Acute and sub-acute oral toxicity were conducted on NMRI mice and Wistar rats. The behaviour and adverse effects were recorded during the 14 days of the acute study. For the subacute test, biochemical parameters, food and water consumption, and morphological parameters were determined. The anti-motility activities were evaluated on Pseudomonas aeruginosa PA01 and Escherichia coli AG100, using specific concentrations of Agar as required by the method.

Results: HEASG induced inhibition of keratinocytes cell growth with an $I_{50}$ of $1302 \pm 60 \mu \mathrm{g} / \mathrm{mL}$. For the acute toxicity study in mice, the single dose of extract of $2000 \mathrm{mg} / \mathrm{kg}$ body weight caused no deaths and no behavioural changes were observed; therefore, the median lethal dose $\left(L_{50}\right)$ of $H E A S G$ was calculated to $5000 \mathrm{mg} / \mathrm{kg}$ body weight. In Wistar rats, no mortality was observed at 250, 500 and $1000 \mathrm{mg} / \mathrm{kg} /$ day during the 28-day subacute oral toxicity study. The weights of both females and males increased globally over time, regardless of the batch. No statistically significant differences were registered for organ weights and biochemical parameters, except for chloride for biochemical parameters. Water and food consumption did not change significantly. Furthermore, no macroscopic changes in organ appearance were observed. Regarding anti-motility activity, the extract has reduced the swarming motility of PA01 and AG100 significantly at the concentration of $32 \mu \mathrm{g} / \mathrm{mL}(P<0.001)$. The extract has reduced the swimming motility $(P<0.01)$ of PA01 but not AG100.
\end{abstract}

Conclusions: The results suggest that hydroethanolic extract of $A$. senegal leaves has significant activity against bacterial motility and relatively low toxicity.

Keywords: Acacia senegal, Oral toxicity, Bacterial motility, Cytotoxicity

\footnotetext{
* Correspondence: dofinirene@gmail.com

'UMR_MD1, U-1261, INSERM, SSA, IRBA, MCT, Faculté de Pharmacie,

Université Aix-Marseille, 13385 Marseille, France

2Département de Médecine et Pharmacopée Traditionnelle/ Pharmacie

(MEPHATRA-PH), Institut de Recherche en Sciences de la Santé (IRSS/CNRST),

Ouagadougou 0303 BP 7047, Burkina Faso

Full list of author information is available at the end of the article
}

C C The Author(s). 2021 Open Access This article is licensed under a Creative Commons Attribution 4.0 International License, which permits use, sharing, adaptation, distribution and reproduction in any medium or format, as long as you give appropriate credit to the original author(s) and the source, provide a link to the Creative Commons licence, and indicate if changes were made. The images or other third party material in this article are included in the article's Creative Commons licence, unless indicated otherwise in a credit line to the material. If material is not included in the article's Creative Commons licence and your intended use is not permitted by statutory regulation or exceeds the permitted use, you will need to obtain permission directly from the copyright holder. To view a copy of this licence, visit http://creativecommons.org/licenses/by/4.0/ The Creative Commons Public Domain Dedication waiver (http://creativecommons.org/publicdomain/zero/1.0/) applies to the data made available in this article, unless otherwise stated in a credit line to the data. 


\section{Background}

Plants have always been very widely used by humans, as a food source and also for their curative/preventive effects against several diseases [1, 2]. Today, medicinal plants present undeniable medicinal interest [3] because of the many natural therapeutic products they produce that can be use in addition face to the continuous increase of resistance towards synthetic molecules such as antibiotics $[4,5]$. Moreover, the toxicity associated to the repeated use of synthetic drugs contributes to a greater demand for phytotherapy and natural extracts. Acacia senegal is the plant species belonging of the Fabaceae family, well known in African traditional medicine. Traditionally, the bark of trunks, roots and gum are used in Burkina Faso against respiratory infections, influenza and sinusitis, sexually transmitted diseases, diarrhoea, gastric ulcers, haemorrhoids etc. [6, 7]. The leaves are used as a feed supplement for cattle [8]. Pharmacological data has shown that ethyl acetate extract from the stem bark of A. Senegal causes a significant decrease in blood glucose, Total chlolesterol serum (TC serum), Tissue transglutaminase serum (serum TTG), Low density lipoprotein serum (LDL serum), serum urea and creatinine and increase in serum high density lipoprotein (HDL) on the 16th day after administration in albino rats rendered diabetic to alloxan [9]. Also, the hydroethanolic extract of $A$. senegal pods significantly reduced acute hepatotoxicity induced by carbon tetrachloride (CCL4) in Wistar albino rats [10]. Ethanolic extract from the leaves decreased sucrose enzyme activity, promoted control of carbohydrate hydrolysis, and therefore reduced the increase in postprandial blood glucose levels in diabetic rats [11]. A study carried by Seif MM and collaborators [12] evaluated the efficacy of Acacia senegal extracts for the improvement of hepatic and cerebral toxicity induced by Di-2- Ethylhexyl phthalate (DEHP). Sprague Dawley rats, in which acute hepatotoxicity and neurotoxicity were induced by DEHP, were treated orally with a $70 \%$ ethanolic extract of $A$. senegal pods for 28 days under several conditions. Results showed that the $A$. senegal extract restored antioxidant enzyme activities to normal, reducing the level of LPO in both tissues. In addition, the extract improved the levels of brain amino acids, monoamines and their metabolites. Methanolic extract from the bark of the stem showed 100\% mortality against worms adult Fasciola gigantica at concentrations of 1000, 500 and $250 \mathrm{ppm}$ after 6, 12 and $24 \mathrm{~h}$ respectively [13]. Research conducted by Mudi and Salisu [14] demonstrated that the hexanic fraction of the bark of the stem of $A$. senegal is active against respiratory pathogenic bacteria, notably Klebsiella pneumonia and Streptococcus pneumoniae. Furthermore, methanolic and ethanolic extracts of $A$. senegal trunk bark showed antibacterial activity against $K$. pneumoniae, Proteus vulgaris, Salmonella Typhi, Shigella dysenteriae and E. coli and the toxicity studies of the ethanol extracts revealed that they exhibited no significant toxicity $\left(\mathrm{LC}_{50}\right.$ of $100 \mu \mathrm{g} / \mathrm{ml}$ ) against Artemia salina [15]. Recent studies have shown that $A$. senegal hydroethanolic extract synergizes antibacterial activities of phenicol antibiotics when used in combination against resistant Gram negative bacteria. A permeabilizing effect of the extract on the outer membrane of these multi-drug resistant bacteria was also reported [16]. Also, given the high demand for its gum arabic, and the synergistic activity with the phenicol family proven on multi-resistant bacterial strains, the safety of use and the innocuousness remain little documented. With the importance of $A$. senegal in the field of phytotherapy and the place it occupies in projects (Great Green Wall) involving several Sahelian countries, we perform this work in order to evaluate the possible cytotoxic effects and risks of the acute and subacute toxicity of the hydroethanolic extract of $A$. senegal leaves, and also the capability of this extract to inhibit bacterial motility are determined for evaluating the safety of use of Acacia senegal species.

\section{Methods}

\section{Plant material}

Leaves of Acacia senegal (L) willd. Were collected in June and August in the area of Saaba to Gonsé, located twenty kilometres from Ouagadougou (Burkina Faso), after validation of the thesis protocole research at University of Joseph Ki-Zerbo of Ouagadougou. The plant identification was made at Université Joseph Ki-Zerbo of Ouagadougou at the Laboratory of Plant Biology and Ecology by Pr. Amadé Ouedraogo, where the voucher specimen is deposited under the reference number 6896/17257. The leaves were dried at ambient temperature under ventilation in the shade for 2 weeks. The dried leaves were ground and stored for extraction.

\section{Preparation of the extract}

One hundred grams of Acacia senegal leaves powder was macerated with petroleum ether $(500 \mathrm{ml})$ at room temperature for $24 \mathrm{~h}$ as a first step. Afterwards, the mixture was filtered through the Whatman No.1 filter; the marc was dried and macerated again in $70 \%$ ethanol (V/ V) overnight. The supernatant was collected, concentrated and frozen before being lyophilized to obtain the powder of $A$. senegal extract (HEASG).

\section{In vitro cytotoxicity evaluation}

$\mathrm{HaCaT}$ (human Squamous Cell Carcinoma from Tongue) cells (ATCC ${ }^{\oplus}$ CRL-1624 ${ }^{\mathrm{TM}}$ ) were obtained from ATCC ${ }^{\ominus}$ culture collection, cultured in Dulbecco's modified Eagle's medium containing 10\% fetal bovine serum and penicillin $(100 \mathrm{IU} / \mathrm{ml}) /$ streptomycin $(100 \mu \mathrm{g} / \mathrm{ml})$ 
(Invitrogen, Carlsbad, CA, USA), under a humidified atmosphere of $5 \% \mathrm{CO}_{2}$ at $37^{\circ} \mathrm{C}$.

Human keratinocytes $(\mathrm{HaCaT})$ were seeded into 96well tissue culture plates $\left(0.2 \mathrm{~mL}\right.$ per well), at $1.10^{5}$ cells/ $\mathrm{mL}$ [17], and incubated at $37^{\circ} \mathrm{C}\left(5 \% \mathrm{CO}_{2}\right)$ for $24 \mathrm{~h}$ until semi-confluent. The culture medium was decanted and replaced by $200 \mu \mathrm{L}$ of complete medium containing the appropriate concentrations of the hydroethanolic extract of A. senegal leaves (8 different concentrations), then cells were incubated at $37^{\circ} \mathrm{C}\left(5 \% \mathrm{CO}_{2}\right)$ during $24 \mathrm{~h}$. After incubation, the culture medium was removed. The cells are washed and placed in Neutral Red medium $(50 \mu \mathrm{g} / \mathrm{mL}$ of Neutral Red in the complete medium) and incubated for $3 \mathrm{~h}$ at $37^{\circ} \mathrm{C}\left(5 \% \mathrm{CO}_{2}\right)$. Then the medium is removed, and the cells are washed three times with $0.2 \mathrm{~mL}$ HBSS to remove excess dye. The neutral red medium was removed, and the staining solution $(50 \%$ ethanol, $1 \%$ acetic acid, $49 \%$ distilled water; $50 \mu \mathrm{L}$ per well) was added to the wells. The plates were shaken for 15-20 min at room temperature in the dark [18]. All the test samples and controls were run in triplicates, in independent experiments. A fluorescence-luminescence reader Infinite M200 Pro (TECAN) measured the degree of membrane damage (i.e. the increase of released Neutral Red). The, of each well was read at $540 \mathrm{~nm}$. The results obtained for wells treated with HEASG were compared to those of untreated control wells (HBSS, $100 \%$ viability) and converted to percentage values [19]. The concentration of HEASG, causing $50 \%$ release of the preloaded Neutral Red as compared to the control culture, was calculated using software Graph Pad Prism 5.0. The mean absorbance value of the blank wells (containing only the desorbed Neutral Red solution) was subtracted from the mean OD value of three treated wells (dilutions of extract, positive control or HBSS). The cell viability percentages were estimated as follows:

$$
\text { Viability }(\%)=\frac{\text { Mean OD of test wells-mean OD of blanks }}{\text { Mean OD of negative control-mean OD of blanks }}
$$

\section{Experimental animals}

Healthy Female NMRI mice (5-8 week-old and weighing 22-29 g) and Wistar rats (7-10 week old and weighing 134-204 g) were used in the study, respectively. They were obtained from the pet shop of Institut de Recherche en Sciences de la Santé (IRSS), Ouagadougou, Burkina Faso. The selected animals were kept in their plastic cages for 6 days for acclimatization before testing began under normal laboratory conditions ( $12 \mathrm{~h}$ light/ dark cycle and $25 \pm 2{ }^{\circ} \mathrm{C}$ ). Water and laboratory pellets, enriched with $29 \%$ protein, were freely accessible to the animals. The experimental protocol was carried out following international standard protocols [Guidelines set by the European Union on the protection of animals
(CEC Council 86/609)] and adopted by IRSS, Burkina Faso [20, 21]. All sections of this report adhere to the ARRIVE guidelines for reporting animal research (Additional file 1).

\section{Acute toxicity test}

The acute toxicity test was carried out following to OECD test guideline 423 for acute oral toxicity [22] After a $4 \mathrm{~h}$ fastening period, the mice were weighed, and the dose of HEASG was calculated from the body weight. HEASG was administered orally by gavage in a single dose to the mice according to a sequential procedure. In performing the test, $2000 \mathrm{mg} / \mathrm{kg}$ b.w. of HEASG was used as a starting dose. Two hours after treatment, all animals were observed, and feeding was reestablished. They are then observed at least once daily for 14 days for mortality and signs of toxicity such as changes in skin and fur, eyes, mucus membranes, salivation, convulsion, diarrhoea, lethargy, sleep, and coma $[20,21]$.

\section{Sub-acute toxicity study}

This test was carried in accordance with the OECD test guideline 407 [23]. Briefly, forty rats were randomly selected including 20 females and 20 males. Females involved were nulliparous and non-pregnant. The rats were divided into four groups of 10 animals each (5 males and 5 females); males and females were placed separately in polypropylene cages. Group 1 served as a control and received the control (distilled water), while the rats in Group 2, 3 and 4 were respectively received daily doses of 250,500 and $1000 \mathrm{mg} / \mathrm{kg}$ b.w of the HEASG for 28 days at the same hour. The animals were observed during the first 1 and $4 \mathrm{~h}$ of dosing to examine all adverse toxic markers, behavioural variation and at least twice a day for mortality and morbidity. Body weight and food consumption were reported once weekly. Water consumption was monitored daily for each cage (5 rats per cage) up to 4 weeks. On the 29th day, after overnight fastening, we have proceeded to animals sacrifice. The rats generally anesthetized by intraperitoneal injection of $150 \mathrm{mg} / \mathrm{kg}$ of ketamine. After 10 to $30 \mathrm{~min}$ of ketamine administration, the animals were completely unconscious. They were then placed in the supine position and the abdominal cavity of each rat was opened. Blood samples were collected by cardiac puncture using a $5 \mathrm{~mL}$ syringe, followed in animals death within $5 \mathrm{~min}$. Then vital organs of animals were isolated [20].

\section{Determination of the relative weight of organs}

At the end of HESAG treatment, after overnight fastening, all animals were sacrificed, and vital organs such as heart, kidneys, liver, lung, gonads (testis or ovaries) and 
spleen were isolated and observed macroscopically for any lesions. After that, all organs were dried using hygienic paper and then weighed on a precision balance (Sartorius; precision $0.1 \mathrm{mg}$ ). The relative organ weight ratio (ROW) of each rat was determined as follows [24]:

$$
\text { ROW }(\%)=100 X \frac{\text { Absolute organ weight }(\mathrm{g})}{\text { Body weight of rats on sacrifice day }(\mathrm{g})}
$$

\section{Biochemical parameters}

The blood samples collected in dry vacutainers were centrifuged at $3000 \mathrm{rpm}$ for $10 \mathrm{~min}$ using a centrifuge (ROTOFIX 32A, Mettich Zenfrifugen, Germany); the serum obtained was used for biochemical assays. Blood chemicals tests were carried out using an automatic biochemistry analyzer (Mindray BS-300, China). Biochemical parameters, including total proteins, aspartate aminotransferase, alanine aminotransferase, creatinine, cholesterol, fasting blood glucose, chloride, phosphorus, and magnesium, were determined.

\section{Anti-motility activities Bacterial strains}

The phenotypic and/or genotypic characteristics and minimum inhibitory concentrations are reported in Table 1.

\section{Swimming and swarming motility assays}

The bacterial strains used in our study are obtained from the laboratory collection of research unit UMR-MD1/ MCT, INSERM U1261 of the Aix Marseille University, France. They are stocked in cryotubes containing a 15\% glycerol solution and stored in a freezer - 80 .

For swimming motility, 0.3\% Agar containing $10 \mathrm{~g}$ tryptone, $5 \mathrm{~g}$ yeast extract and $0.5 \% \mathrm{NaCl}$ was used [27]. For swarming motility, LB medium supplemented with $5 \mathrm{~g}$ de glucose and $5 \mathrm{~g}$ of Agar were used [28]. The plant extracts were added to the motility Agar, and DMSO (0.1\%) was added as a control. PA01 and AG 100 were grown to an $\mathrm{OD}_{600}$ of 1.0 , and $\sim 0.2 \mu \mathrm{L}$ of culture was placed on the motility plates using a sterile pipette tip. The diameters of the swimming and swarming halos were measured after $24 \mathrm{~h}$. Each experiment was repeated using three independent cultures.

\section{Statistical analysis}

Statistical analysis was done using ANOVA. Results are shown as mean \pm SD of three determinations. The statistical value of the difference between the treatment and control groups was interpreted by one-way analysis of variance (ANOVA) using Graph Pad Prism 5 (Graph Pad Software, San Diego, CA, USA) followed by Dunnett's multiple comparison tests. Significant differences in treatment were accepted at $P<0.05$.

\section{Results}

\section{Cytotoxicity evaluation}

The percentage viability of $\mathrm{HaCaT}$ cells in the presence of HEASG was determined from OD measurements (Fig. 1). The different concentrations of HEASG increased cell viability up to the dose of $250 \mu \mathrm{g} / \mathrm{mL}$. The cytotoxic effects of HEASG were clearly observed at 1000 and $2500 \mu \mathrm{g} / \mathrm{mL}$ doses, compared to the control with a significant difference $(P<0.001)$. This reflects a strong decrease in the relative amount of live $\mathrm{HaCaT}$ cells with an $\mathrm{IC}_{50}$ (50\% inhibitory concentration) equal to $1302 \pm 60 \mu \mathrm{g} / \mathrm{mL}$.

\section{Acute toxicity study of Acacia senegal leaves hydroethanolic extract in mice}

During the 14 days of observation post-treatment, no deaths were observed in the groups of experimental animals. Per os administration of a single dose of $2000 \mathrm{mg} /$ $\mathrm{kg}$ of HEASG did not induce any significant changes in the mice. According to the acute toxicity class method, HEASG tested can be classified to the 5th toxicity class with an $\mathrm{LD}_{50}$ value estimated to $5000 \mathrm{mg} / \mathrm{kg}$ b.w.

\section{Sub-acute toxicity study}

The results obtained from subacute toxicity study with daily administration at repeated doses $(250,500$ and $1000 \mathrm{mg} / \mathrm{kg}$ ) of HEASG allowed the evaluation of behavioural parameters, water and food consumption, relative weight growth, relative organs weights and biochemical parameters.

\section{Body weight}

At all doses of HEASG tested, no significant behavioural changes were observed in males or females. The weights of males (Fig. 2) and females (Fig. 3) increased in all groups over time. Statistical analysis indicated any significant difference between the treated and the control groups.

Table 1 Bacterial strains used in this study

\begin{tabular}{llll}
\hline Strains & Phenotype & Reference & $\begin{array}{c}\text { MIC (mg/L) } \\
\text { HEASG }\end{array}$ \\
\hline PA01 & P. aeruginosa, Wild type & {$[25]$} & $>512$ \\
AG100 & Parental E. coli K-12 Porint; basal efflux & {$[26]$} & 256 \\
\hline
\end{tabular}

MIC Minimal Inhibitory Concentration, HEASG hydroethanolic Acacia senegal leaves 


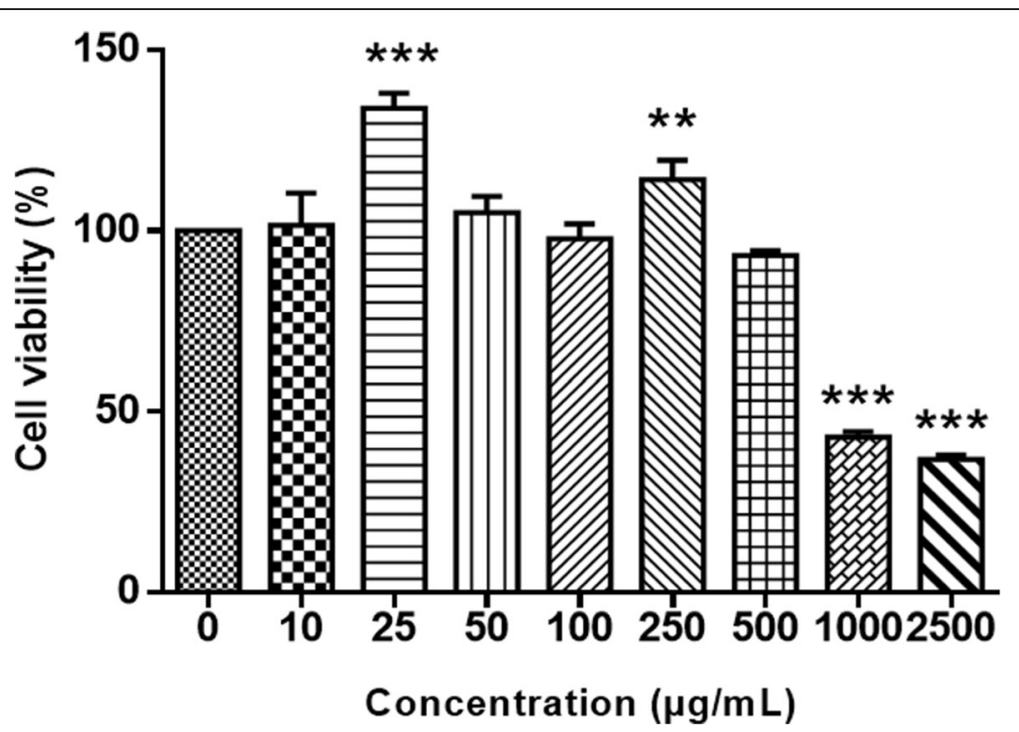

Fig. 1 Effect of different concentration of HEASG on the viability of human keratinocyte cells HaCat. The values are expressed as mean \pm SD of three independent experiments. ${ }^{* * *}$ indicated $p<0.001,{ }^{* *}$ indicated $p<0.01$ versus the untreated control; $n=3$

Water intake and food consumption

Table 2 summarizes water consumption data for the 28 days of observation. No significant variation was observed between control and treated animals groups. Table 3 provides information on food consumption at each dose level compared to the control group. Treated animals at the different doses compared to the control group showed no significant variation in either males or females.

\section{Effect of HEASG on organs weights in rats}

Table 4 showed the effect of the toxicity of HEASG on mean vital relative organ weights in rats. Compared to the mean weight of controls, HEASG did not cause any significant change in mean organ weights in treated rats $(\mathrm{p}<0.05)$.

\section{Effect of HEASG on biochemical parameters of rats}

Daily oral administration repeated at doses of 250, 500 and $1000 \mathrm{mg} / \mathrm{kg}$ of HEASG allowed the evaluation of biochemical parameters. Examination of serum electrolytes did not show statistically significant variation between the treated female or male groups and their respective control groups (Table 5). These results indicated that orally administration of HEASG at doses of

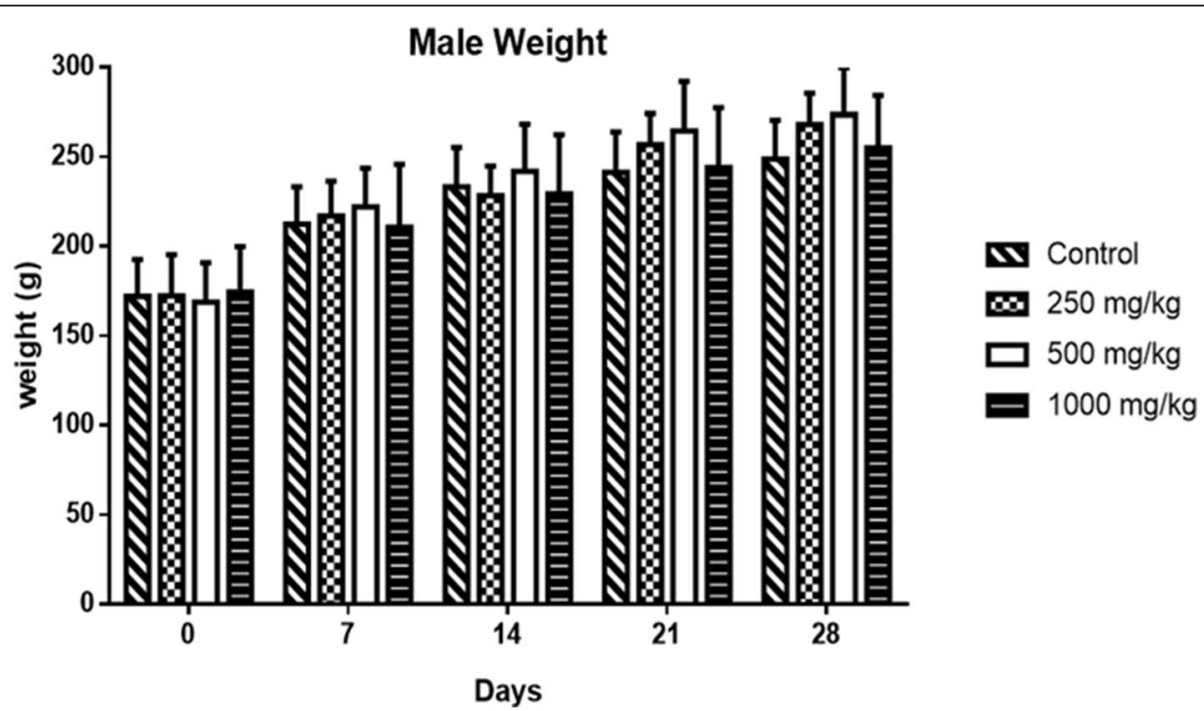

Fig. 2 Mean absolute weight of control and treated males rats groups with different doses of HEASG. Mean and Standard deviation are presented $(n=5)$ 


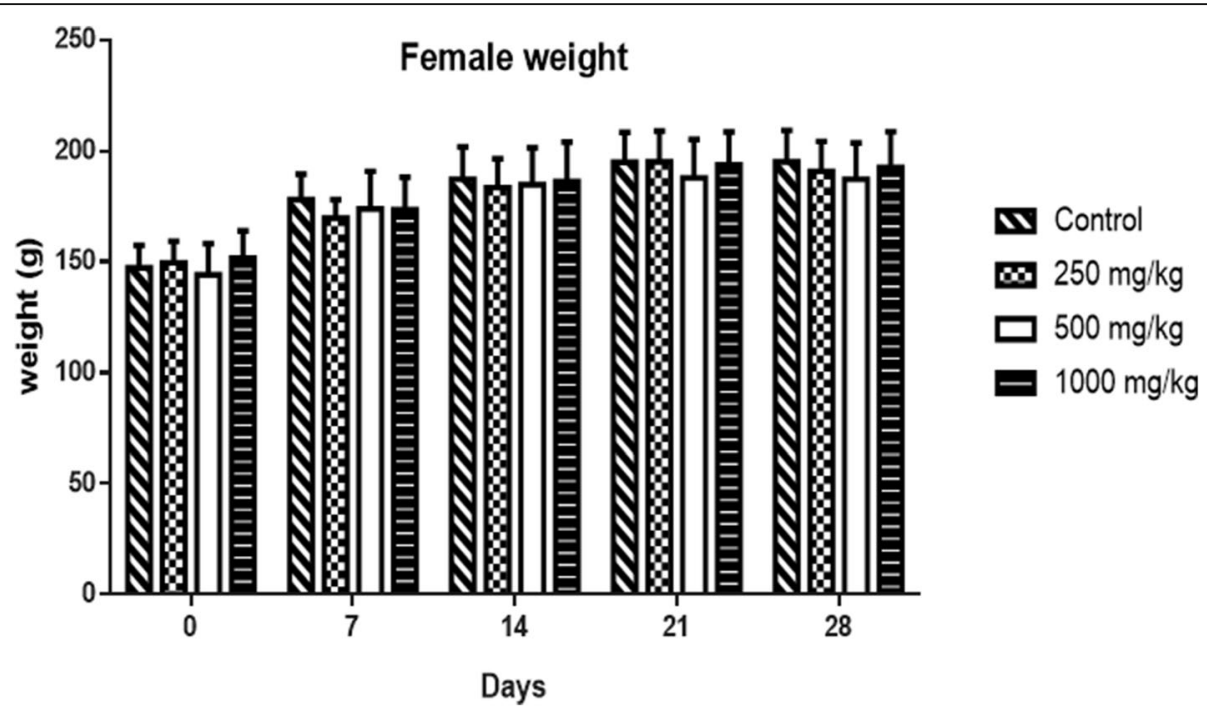

Fig. 3 Mean absolute weight of control and treated females rats groups with different doses of HEASG. Mean and Standard deviation are presented $(n=5)$

250, 500 and $1000 \mathrm{mg} / \mathrm{kg}$ b.w on rats for 28 consecutive days did not cause statistically significant changes in blood serum biochemical parameters such as sodium, potassium, calcium, phosphorus, aspartate aminotransferase (AST), alanine aminotransferase (ALT), total proteins, fasting blood glucose, creatinine and total cholesterol levels when compared to control groups. However, a statistically significant difference in chloride level was observed in the group treated at a dose of 250 and $500 \mathrm{mg} / \mathrm{kg}$ b.w. when compared to control groups $(P<0.01)$ in both sexes.

\section{Motility assays}

The effects of the hydroethanolic extract at sub-MIC levels (32 to $512 \mu \mathrm{g} / \mathrm{mL}$ ) on the swimming, and swarming motilities of PA01 and AG100 were investigated. The extract has reduced swimming and swarming motility in comparison to the control (no treated). More

Table 2 Mean daily water intake (mL/day/rat) during 28 days of treatment with HEASG

\begin{tabular}{llllll}
\hline Dose of HEASG & SEX & Week 1 & Week 2 & Week 3 & Week 4 \\
\hline Control & F & $35 \pm 7$ & $35 \pm 7$ & $30 \pm 5$ & $31 \pm 3$ \\
& M & $48 \pm 14$ & $42 \pm 8$ & $37 \pm 2$ & $39 \pm 6$ \\
$250 \mathrm{mg} / \mathrm{kg}$ & $\mathrm{F}$ & $30 \pm 5$ & $31 \pm 2$ & $27 \pm 5$ & $32 \pm 3$ \\
& $\mathrm{M}$ & $47 \pm 11$ & $44 \pm 8$ & $36 \pm 5$ & $40 \pm 6$ \\
$500 \mathrm{mg} / \mathrm{kg}$ & $\mathrm{F}$ & $34 \pm 10$ & $32 \pm 2$ & $28 \pm 2$ & $28 \pm 1$ \\
& $\mathrm{M}$ & $52 \pm 13$ & $44 \pm 10$ & $39 \pm 6$ & $42 \pm 4$ \\
$1000 \mathrm{mg} / \mathrm{kg}$ & $\mathrm{F}$ & $31 \pm 4$ & $31 \pm 3$ & $27 \pm 6$ & $33 \pm 5$ \\
& M & $43 \pm 10$ & $41 \pm 9$ & $40 \pm 3$ & $43 \pm 5$ \\
\hline
\end{tabular}

Mean and standard déviation are reported as follows $(n=10 ; 5 /$ sex). $M$ Male, $F$ Female interestingly, the different concentrations of HEASG had variable impacts on swimming and swarming motilities. Swimming motility of PA01 was inhibited with values corresponding to approximately 43 and $64 \%$ of control at concentrations of 32 and $64 \mu \mathrm{g} / \mathrm{mL}$, respectively (Fig. 4A).

The swarming motility of PA01 also decreased with level of 55 and $63 \%$ compared to control at concentrations of 32 and $64 \mu \mathrm{g} / \mathrm{mL}$, respectively (Fig. $5 \mathrm{~A}$ ).

The Fig. 6A shows that HEASG inhibits the swarming motility of AG100 from 32 to $512 \mathrm{mg} / \mathrm{L}$. The results showed that with a concentration of 32 and $64 \mu \mathrm{g} / \mathrm{mL}$, we obtained a swarming motility inhibition of 70 and $73 \%$ of control respectively. In contrast to swarming (Fig. 7A), HEASG at different concentrations did not affect the swimming motility comparatively the control.

Table 3 Mean daily food consumption (g/day/rat) during 28 days of treatment with hydroethanolic extract of $A$. senegal leaves

\begin{tabular}{llllll}
\hline Dose of HEASG & SEX & Week 1 & Week 2 & Week 3 & Week 4 \\
\hline Control & F & 20.71 & 19.71 & 19.80 & 17.20 \\
& M & 22.88 & 22.14 & 21.42 & 20.28 \\
$250 \mathrm{mg} / \mathrm{Kg}$ & F & 17.45 & 18.02 & 17.94 & 16.68 \\
& $\mathrm{M}$ & 23.20 & 24.51 & 21.42 & 23.20 \\
$500 \mathrm{mg} / \mathrm{Kg}$ & $\mathrm{F}$ & 17.54 & 16.80 & 16.25 & 16.78 \\
& $\mathrm{M}$ & 24.91 & 26.80 & 24.45 & 21.85 \\
$1000 \mathrm{mg} / \mathrm{Kg}$ & $\mathrm{F}$ & 17.02 & 17.34 & 16.00 & 15.57 \\
& $\mathrm{M}$ & 18.14 & 21.02 & 26.51 & 21.34 \\
\hline
\end{tabular}

Mean and standard déviation are reported as follows ( $n=10 ; 5 /$ sex). M Male, $F$ Female 
Table 4 Mean relative organ weights (\%) of rats after 28 days of treatment with HEASG

\begin{tabular}{llllll}
\hline Organs & Sex & Control & $\mathbf{2 5 0} \mathbf{~} \mathbf{g} / \mathbf{K g}$ & $\mathbf{5 0 0} \mathbf{~} \mathbf{g} / \mathbf{K g}$ & $\mathbf{1 0 0 0} \mathbf{~} \mathbf{g} / \mathbf{K g}$ \\
\hline Lung & $\mathrm{F}$ & $0.55 \pm 0.04$ & $0.56 \pm 0.08$ & $0.52 \pm 0.04$ & $0.54 \pm 0.12$ \\
& $\mathrm{M}$ & $0.53 \pm 0.02$ & $0.46 \pm 0.03$ & $0.45 \pm 0.03$ & $0.49 \pm 0.07$ \\
Kidney & $\mathrm{F}$ & $0.65 \pm 0.03$ & $0.67 \pm 0.08$ & $0.64 \pm 0.05$ & $0.63 \pm 0.06$ \\
& $\mathrm{M}$ & $0.64 \pm 0.05$ & $0.65 \pm 0.05$ & $0.64 \pm 0.05$ & $0.64 \pm 0.07$ \\
Spleen & $\mathrm{F}$ & $0.23 \pm 0.02$ & $0.21 \pm 0.02$ & $0.23 \pm 0.03$ & $0.23 \pm 0.04$ \\
& $\mathrm{M}$ & $0.19 \pm 0.03$ & $0.20 \pm 0.03$ & $0.17 \pm 0.02$ & $0.20 \pm 0.10$ \\
Liver & $\mathrm{F}$ & $3.20 \pm 0.60$ & $3.00 \pm 0.30$ & $2.90 \pm 0.30$ & $3.00 \pm 0.30$ \\
& $\mathrm{M}$ & $2.50 \pm 0.10$ & $2.90 \pm 0.20$ & $2.80 \pm 0.20$ & $2.90 \pm 0.30$ \\
Heart & $\mathrm{F}$ & $0.34 \pm 0.03$ & $0.33 \pm 0.03$ & $0.35 \pm 0.02$ & $0.31 \pm 0.04$ \\
& $\mathrm{M}$ & $0.35 \pm 0.03$ & $0.33 \pm 0.02$ & $0.33 \pm 0.02$ & $0.31 \pm 0.04$ \\
Gonads & $\mathrm{F}$ & $0.06 \pm 0.01$ & $0.05 \pm 0.02$ & $0.07 \pm 0.02$ & $0.06 \pm 0.02$ \\
& $\mathrm{M}$ & $1.20 \pm 0.10$ & $1.17 \pm 0.04$ & $1.23 \pm 0.12$ & $1.10 \pm 0.10$ \\
\hline
\end{tabular}

Mean and standard deviation are represented ( $n=10 ; 5 /$ sex). M Male, $F$ Female. $p<0.05$

\section{Discussion}

Extract of $A$. senegal has previously shown an attractive antibacterial activity $[7,16]$. In the present work the acute and subacute toxicity of the hydroethanolic extract of leaves is evaluated.

The cytotoxic activity results obtained show that the treatment of $\mathrm{HaCaT}$ cells with low concentrations of Acacia senegal leaves extracts exhibited no cytotoxic effects when the use of high concentrations $(1000 \mu \mathrm{g} / \mathrm{mL})$ resulted in a noticeable cytotoxicity. According to Kuete and Efferth [29], in normal cell lines the cytotoxicity of plant extracts is important or strong when the $\mathrm{IC}_{50}<$ $40 \mu \mathrm{g} / \mathrm{mL}$; moderate cytotoxicity: $40 \mu \mathrm{g} / \mathrm{mL}<\mathrm{IC}_{50}<120$ $\mu \mathrm{g} / \mathrm{mL}$, low cytotoxicity: $120 \mu \mathrm{g} / \mathrm{mL}<\mathrm{IC}_{50}<400 \mu \mathrm{g} / \mathrm{mL}$ and no cytotoxicity: $\mathrm{IC}_{50}>400 \mu \mathrm{g} / \mathrm{mL}$. It is interesting to notify that the $\mathrm{IC}_{50}(1302 \pm 60 \mu \mathrm{g} / \mathrm{mL})$ observed by $A$. senegal $\mathrm{HE}$ against the normal $\mathrm{HaCaT}$ cell is considerably higher than $400 \mu \mathrm{g} / \mathrm{mL}$ making HEASG a promising candidate for future studies. Also, HEASG is able to potentialize the phenicols activities and permeabilize the bacterial outer membrane $(\mathrm{OM})$ at concentrations of 32 and $64 \mu \mathrm{g} / \mathrm{mL}$ [16] that are non-cytotoxic in the assays reported here.

Table 5 Biochemical parameters of rats after 28 days of treatment with HEASG

\begin{tabular}{|c|c|c|c|c|c|}
\hline Biochemical parameters & Sex & Control & $250 \mathrm{mg} / \mathrm{Kg}$ & $500 \mathrm{mg} / \mathrm{Kg}$ & $1000 \mathrm{mg} / \mathrm{Kg}$ \\
\hline \multirow[t]{2}{*}{ Sodium (mmol/L) } & $\mathrm{F}$ & $139.4 \pm 4.5$ & $143.2 \pm 5.9$ & $139.0 \pm 6.8$ & $150.4 \pm 2.5$ \\
\hline & M & $139.2 \pm 3.1$ & $141.0 \pm 3.3$ & $146.23 \pm 2.4$ & $146.7 \pm 1.3$ \\
\hline \multirow[t]{2}{*}{ Chloride (mmol/L) } & $\mathrm{F}$ & $121.0 \pm 3.0$ & $104.7 \pm 1.5^{*}$ & $105.3 \pm 4.0^{*}$ & $116.3 \pm 6.4$ \\
\hline & M & $122.0 \pm 2.1$ & $100.8 \pm 3.3^{*}$ & $104.8 \pm 1.0^{*}$ & $122.0 \pm 3.0$ \\
\hline \multirow[t]{2}{*}{ Potassium (mmol/L) } & $\mathrm{F}$ & $5.4 \pm 1.0$ & $5.6 \pm 1.2$ & $5.0 \pm 0.4$ & $5.0 \pm 0.6$ \\
\hline & M & $5.8 \pm 0.8$ & $5.9 \pm 0.4$ & $5.0 \pm 0.5$ & $5.8 \pm 0.6$ \\
\hline \multirow[t]{2}{*}{ Calcium (mmol/L) } & $\mathrm{F}$ & $3.5 \pm 0.2$ & $3.1 \pm 0.1$ & $3.1 \pm 0.4$ & $3.3 \pm 0.2$ \\
\hline & M & $3.4 \pm 0.2$ & $3.0 \pm 0.1$ & $3.1 \pm 0.3$ & $3.2 \pm 0.1$ \\
\hline \multirow[t]{2}{*}{ Phosphorus (mmol/L) } & $\mathrm{F}$ & $3.9 \pm 0.6$ & $3.8 \pm 0.3$ & $3.5 \pm 0.3$ & $3.9 \pm 0.6$ \\
\hline & M & $4.5 \pm 0.4$ & $4.2 \pm 0.3$ & $3.7 \pm 0.4$ & $4.2 \pm 0.3$ \\
\hline \multirow[t]{2}{*}{ ASAT (U/L) } & $\mathrm{F}$ & $133.7 \pm 42$ & $123.0 \pm 30$ & $129.8 \pm 58$ & $130.0 \pm 34$ \\
\hline & M & $129.0 \pm 17$ & $112.0 \pm 28$ & $129.0 \pm 31$ & $120.6 \pm 27$ \\
\hline \multirow[t]{2}{*}{ ALAT (U/L) } & $\mathrm{F}$ & $36.5 \pm 6.8$ & $35.5 \pm 3.1$ & $34.3 \pm 9.8$ & $39.0 \pm 9.4$ \\
\hline & M & $43.6 \pm 6.2$ & $40.8 \pm 6.5$ & $38.0 \pm 3.0$ & $46.2 \pm 6.0$ \\
\hline \multirow[t]{2}{*}{ Total protein (g/L) } & $\mathrm{F}$ & $61.8 \pm 4.2$ & $63.8 \pm 4.1$ & $62.5 \pm 3.3$ & $64.6 \pm 3.1$ \\
\hline & M & $61.5 \pm 2.9$ & $56.9 \pm 1.2$ & $61.0 \pm 2.0$ & $65.5 \pm 3.1$ \\
\hline \multirow[t]{2}{*}{ Fasting blood glucose (mmol/L) } & $\mathrm{F}$ & $6.2 \pm 0.8$ & $4.6 \pm 0.6$ & $5.4 \pm 0.1$ & $5.4 \pm 1.1$ \\
\hline & M & $4.5 \pm 0.7$ & $4.4 \pm 0.9$ & $4.3 \pm 1.2$ & $4.4 \pm 0.6$ \\
\hline \multirow[t]{2}{*}{ Creatinine $(\mu \mathrm{mol} / \mathrm{L})$} & $\mathrm{F}$ & $67.5 \pm 0.5$ & $64.7 \pm 2.9$ & $62.0 \pm 2.7$ & $66.8 \pm 1.2$ \\
\hline & M & $60.1 \pm 5.2$ & $60.6 \pm 6.3$ & $56.8 \pm 3.9$ & $61.7 \pm 4.9$ \\
\hline \multirow[t]{2}{*}{ Total cholesterol (mmol/L) } & $\mathrm{F}$ & $1.30 \pm 0.30$ & $1.20 \pm 0.40$ & $1.10 \pm 0.05$ & $1.30 \pm 0.30$ \\
\hline & $M$ & $1.70 \pm 0.20$ & $1.30 \pm 0.03$ & $1.42 \pm 0.05$ & $1.50 \pm 0.30$ \\
\hline
\end{tabular}

Mean and standard deviation are represented $\left(n=10 ; 5 /\right.$ sex). M Male, F Female, ${ }^{*}$ indicate statistically significant difference in values $(p<0.05)$ compared to control. Aspartate aminotransferase (AST); alanine aminotransferase (ALT) 


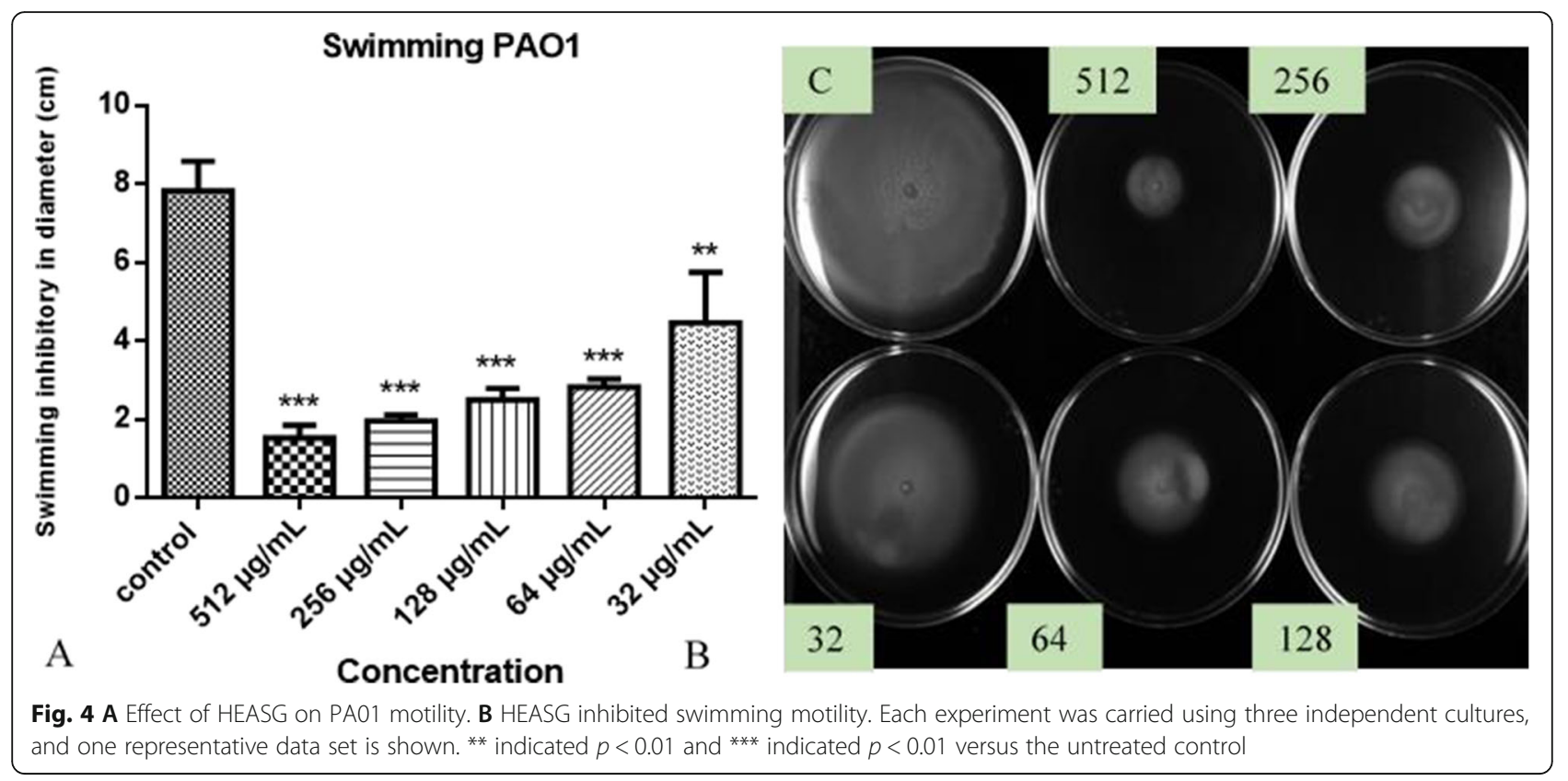

In the acute toxicity study, during the 14-day observation period, no adverse effect or mortality was observed at the single administration dose of $2000 \mathrm{mg} / \mathrm{kg}$ b.w. According to OECD guideline 423 , the $\mathrm{LD}_{50}$ is estimated at $5000 \mathrm{mg} / \mathrm{kg}$ orally and subsequently, the plant extract corresponds to the 5th toxicity class, i.e. products with relatively low acute oral toxicity.

Likewise, the subacute treatment showed that HEASG at doses of 250,500 and $1000 \mathrm{mg} / \mathrm{kg} /$ day during 28 days did not produce any deaths or clinical signs of toxicity.

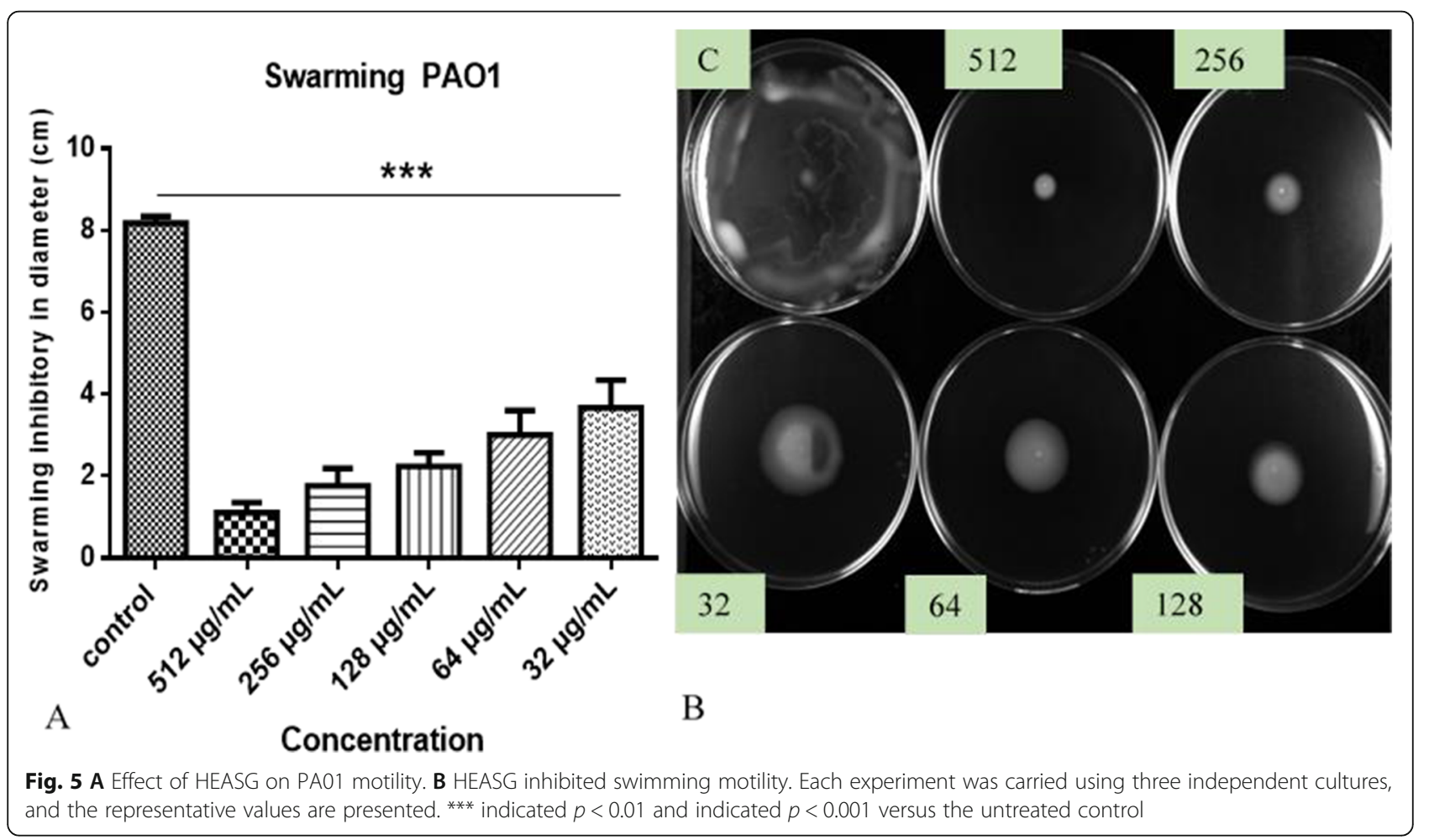




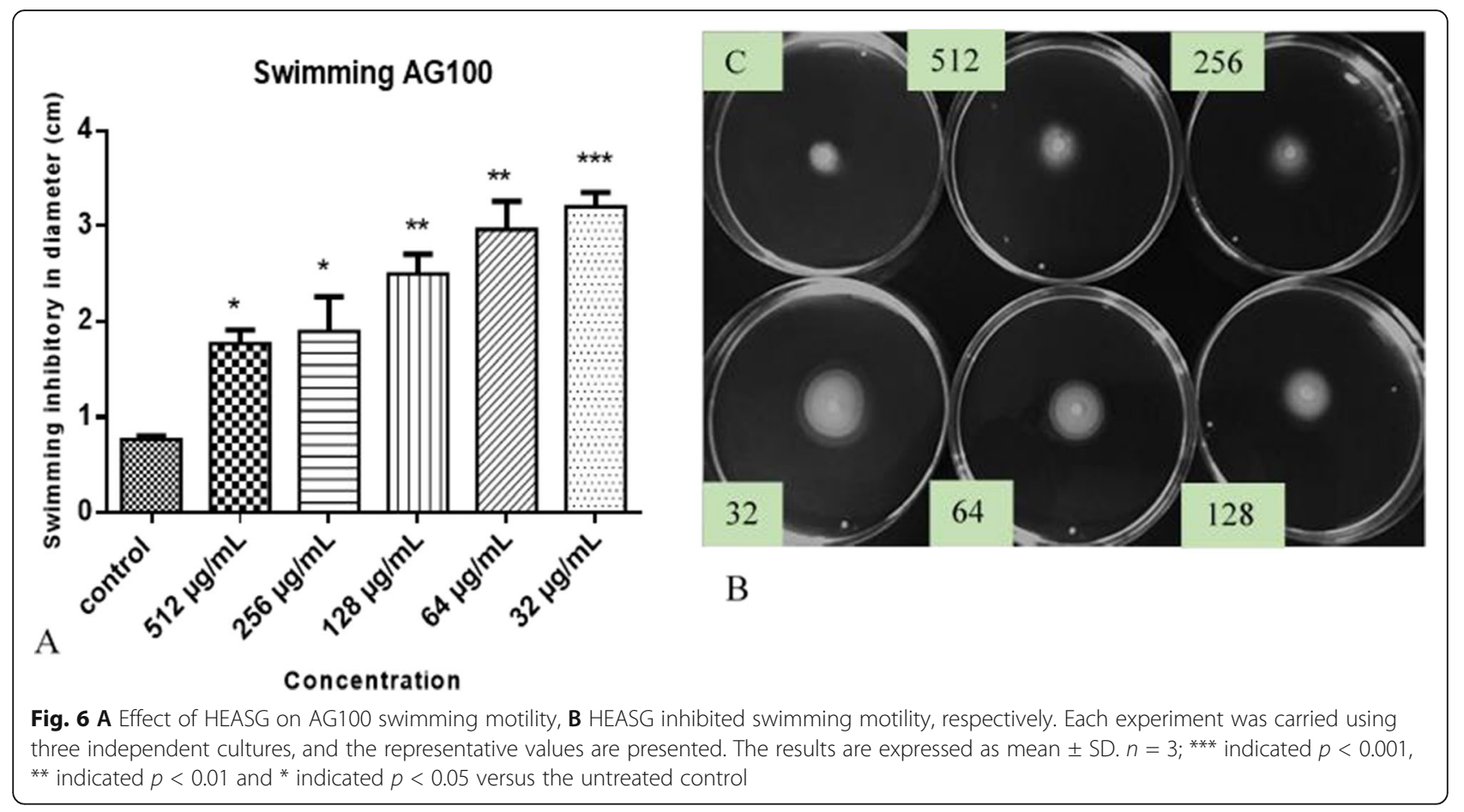

Additionally the body weight, water and food intake were not altered during the treatment period an indicator of the absence of adverse effects of drugs and chemicals under these conditions [30, 31].

In the same way, the treatment with HEASG leaves did not change the biochemical parameters analyzed, except for a decrease $(P<0.05)$ in chloride serum levels in the groups treated with HEASG leaves at 250 and $500 \mathrm{mg} / \mathrm{kg}$ in both sexes. Chloride is the anion most present in serum, and its essential role is to maintain electroneutrality [32]. The variation in the chloride level in this study is not dose-dependent, since with the
A

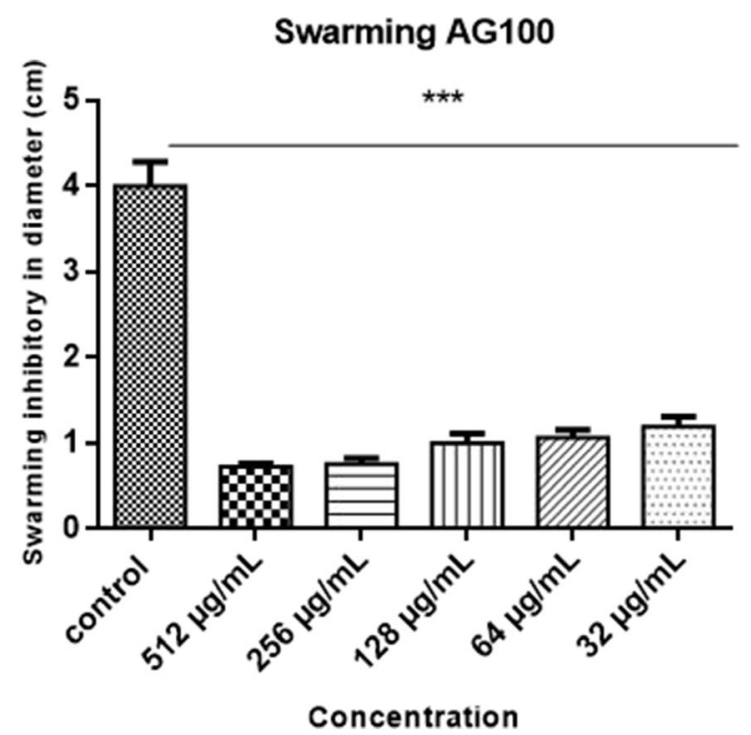

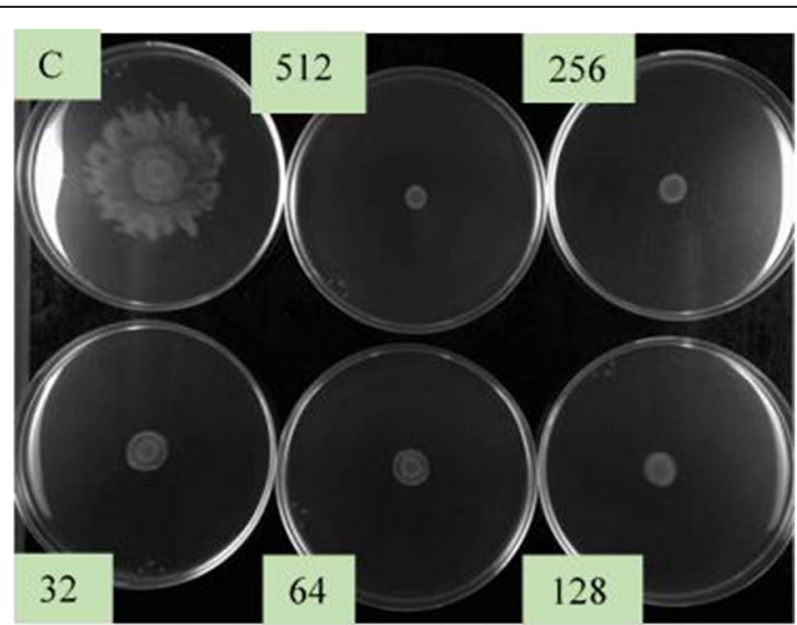

B

Fig. 7 A Effect of HEASG on AG100 swimming motility, B HEASG inhibited swimming motility, respectively. Each experiment was carried using three independent cultures, and the representative values are presented. The results are expressed as mean \pm SD. $n=3 ;{ }^{* * *}$ indicated $p<0.001$, ** indicated $p<0.01$ and * indicated $p<0.05$ versus the untreated control 
highest dose $(1000 \mathrm{mg} / \mathrm{kg})$ we have similar levels with the control group. Several studies have reported the toxicity of plant extracts on liver and kidney function and creatinine and transaminases were used as a marker of toxicity for kidney and liver, respectively [33, 34]. The preservation of the different values (creatinine, AST and ALT) indicates the absence of any adverse activity on these vital organs following the administration of the different doses of HEASG. The relative kidney and liver weights of the treated groups showed no significant differences and macroscopic examination revealed no notable damage. The other vital organs (spleen, heart, lungs, and gonads) also showed no noticeable damage and significant variation of the relative weight (Table 4).

Many studies have reported different types of movement such as swimming, swarming and twitching in PA01, $[35,36]$. These motilities play a significant role in biofilm formation and bacterial virulence [35, 37]. The different types of motility are due to the presence of surface bacterial appendages, such as flagella and pili [38]. HEASG's study against the motility of $P$. aeruginosa and $E$. coli showed that $A$. senegal extract inhibits both the swimming and swarming motility of PA01. However, the same extract had no effect on swimming motility but reduced the swarming motility of AG100. Several authors have shown that plant extracts or plant-derived compounds have similar impacts on bacterial motility. Jin-Hyung Lee et al. [39] demonstrated that Carex dimorpholepis extract and trans-resveratrol clearly reduced swimming motility and suppressed swarming motility of $E$. coli enterohemorrhagic O157: H7 (EHEC). Also, Mallotus japonica extract increased in swimming motility without changing swarming motility. Other authors also reported that extracts $(100 \mu \mathrm{g} / \mathrm{mL})$ of cranberry and pomegranate rich in proanthocyanidins (PAC) and ellagitannins respectively, blocked swarming motility, but did not block swimming motility or twitching into PA01 [40] The proanthocyanidins present in cranberries are condensed tannins composed of catechin and epicatechin monomers which are different from hydrolyzable tannins such as ellagitannins that predominate in pomegranates [41]. A recent study reports tannins, also quantifying condensed and hydrolyzable tannins in the hydroethanolic extract of the leaves of A. senegal [16]. The recorded anti-swarming and anti-swimming activities could be attributed to the tannins contained in the A. senegal extract.

On the other hand, E. coli is responsible for nearly 95\% of urinary tract infections [42]. The infection is triggered by bacterial adhesion to the uroepithelium, followed by multiplication and bacterial colonization of the urinary tract [43]. A research study conducted by Amy B. Howell [44] had already attributed the anti- adhesion property to proanthocyanidins. Besides, swimming and swarming motilities positively influence biofilm development in E. coli and P. aeruginosa [45-47]. These results pave the way for the search for new antiswarming and anti-swimming molecules in the treatment of certain bacterial diseases such as urinary tract infections and opportunistic diseases caused by Gramnegative bacteria.

\section{Conclusion}

The study demonstrated that HEASG could be considered as relatively safe in terms of toxicity since no significant lethality and noticeable adverse biochemical and morphological effects are observed in acute or sub-acute toxicity studies in rats. HEASG is non-cytotoxic at concentrations able to enhance antibiotics activities and permeabilize the outer membrane of Gram-negative bacteria. The study also demonstrated the effect of HEASG on the swarming and swimming motility of PA01 and AG100. Further work is needed to precisely determine the mode of action of the active molecules. Bacterial motility is involved in biofilm and quorum formation, and also in bacterial virulence in various nosocomial infections. Further research on the efficacy of HEASG on bacterial membrane organization involved in biofilm formation and virulence will be engaged in the future.

\section{Abbreviations \\ DMSO: Diméthylsulfoxyde; HEASG: Hydroethanolic Acacia segenal; LB: Luria Bertani; MDR: Multi Drug Resistant; MIC: Minimal Inhibitory Concentration; OM: Outer Membrane; CCL4: Carbon tetrachloride; AST: Aspartate aminotransferase; ALT: Alanine aminotransferase; $I_{50}: 50 \%$ inhibitory concentration; LD 50 : Median lethal dose; OECD: Organization for Economic Cooperation and Development; LDL: Low density lipoprotein; HDL: High density lipoprotein; TTG: Tissue transglutaminase; TC: Total cholesterol; DEHP: Di-2- Ethylhexyl phthalate; LPO: Lipid peroxidation; OD: Optical Density; PAC: proanthocyanidins}

\section{Supplementary Information}

The online version contains supplementary material available at https://doi. org/10.1186/s12906-021-03348-5.

\section{Additional file 1.}

\section{Acknowledgements}

We thank Julia Vergalli who spent the countless hours helping us conduct this study.

\section{Authors' contributions}

RDM performed the experiments and wrote the manuscript. MN, GGO, SI and $A B$ analyzed data. Besides revising the manuscript, $A D R, A H, H M K, C D G$ and JMP designed, coordinated, and supported this study. All authors have read and approved the version to be published and agreed to be accountable for all aspects of this work.

\section{Funding}

We thank Campus France, IRSS/ CNRST and the French Embassy in Burkia Faso for their funding support. 


\section{Availability of data and materials}

The datasets generated and analyzed during the current study are available from the corresponding author on reasonable request. All data generated or analyzed during this study are included in this published article.

\section{Declarations}

\section{Ethics approval and consent to participate}

The experimental protocol was carried out following international standard protocols [Guidelines set by the European Union on the protection of animals (CEC Council 86/609)] and adopted by IRSS, Burkina Faso. The ethics approval has been accorded by the ethic committee of the University Joseph KI-ZERBO (Approval number: CE-UOI/2019-04). The sections of this report join to the ARRIVE Guidelines for reporting animal research [48]. A completed ARRIVE guidelines checklist is included in Supplementary information. This collaborative work was performed in accordance with the Convention on Biological Diversity and the Nagoya protocol and compliance with laws in force in Burkina. Provider (IRSS/CNRST- Burkina Faso) and users (U1261, UMR_MD1, Aix Marseille University/ France) have mutually agreed for equitable sharing benefits in case derivatives arising from this work will be patented.

\section{Consent for publication}

Not applicable for that section.

\section{Competing interests}

The authors declare that they have no competing interests.

\section{Author details}

'UMR_MD1, U-1261, INSERM, SSA, IRBA, MCT, Faculté de Pharmacie, Université Aix-Marseille, 13385 Marseille, France. ${ }^{2}$ Département de Médecine et Pharmacopée Traditionnelle/ Pharmacie (MEPHATRA-PH), Institut de Recherche en Sciences de la Santé (IRSS/CNRST), Ouagadougou 0303 BP 7047, Burkina Faso. ${ }^{3}$ Laboratoire de Biochimie et de Chimie Appliquée (LABIOCA), Université Pr Joseph Ki-Zerbo, Ouagadougou 0303 BP 848, Burkina Faso. ${ }^{4}$ Unité Mixte de Recherche Internationale - Environnement, Santé et Sociétés (UMI 3189, ESS) CNRST (Ouagadougou, Burkina Faso) / CNRS (Marseille, France)/ UCAD-UGB (Dakar, Sénégal)/ USTTB, Bamako, Mali. ${ }^{5}$ Institut Méditerranéen de Biodiversité et d'Ecologie marine et continentale (IMBE), Aix-Marseille Université, UMR CNRS IRD Avignon Université, Campus Timone - Faculté de Pharmacie, 27, boulevard Jean-Moulin, F-13385 Marseille cedex 05, France.

\section{Received: 4 November 2020 Accepted: 9 June 2021}

Published online: 29 June 2021

\section{References}

1. Goswami HK, Ram HK. Ancient Food Habits Dictate that Food Can Be Medicine but Medicine Cannot Be "Food"!! Medicines. 2017;4. https://doi. org/10.3390/medicines4040082.

2. Sofowora A, Ogunbodede E, Onayade A. The Role and Place of Medicinal Plants in the Strategies for Disease Prevention. Afr J Tradit Complement Altern Med. 2013;10:210-29.

3. McGaw L, Srivastava AK, Lin C-H, Steenkamp V. Book Review: Medicinal Plants for Holistic Healing. Front Pharmacol. 2019;10. https://doi.org/10.33 89/fphar.2019.01053.

4. Kyaw BM, Arora S, Lim CS. Bactericidal antibiotic-phytochemical combinations against methicillin resistant Staphylococcus aureus. Braz J Microbiol. 2012;43:938-45.

5. Mun S, Joung D, Kim S, Park S, Seo Y, Gong R, et al. The mechanism of antimicrobial activity of sophoraflavanone $B$ against methicillin-resistant Staphylococcus aureus. Foodborne Pathog Dis. 2014;11:234-9.

6. Kerharo J, Adam JG. La Pharmacopée sénégalaise traditionnelle: Plantes médicinales et toxiques. J Agric Trop Bot Appliquée. 1974;21:76-7.

7. Magnini RD, Hilou A, Millogo-Koné H, Compaore S, Pagès J-M, Davin-Regli. A Review on ethnobotanical uses, biological activities and phytochemical aspects of Acacia senegal (L.) Willd. and Acacia seyal Delile. (Fabaceae). Int J Plant Sci Hortic. 2020;2:32-55.

8. Bussmann RW. Ethnobotany of the Samburu of Mt. Nyiru, South Turkana, Kenya. J Ethnobiol Ethnomed. 2006;2:35.
9. Batra S, Batra N, Nagori BP. In Vitro Study of Acacia senegal (L.) Willd. on Isolated Rat Hemi-Diaphragm by Glucose Uptake Method. Int J Med Res Rev. 2013;1:611-6.

10. Pal R, Hooda MS, Bias CS, Singh J. Hepatoprotective activity of Acacia senegal pod against carbon tetrachloride-induced hepatotoxicity in rats. Int J Pharm Sci. 2014;26:165.

11. I.S.Abdelhady M, Youns M. In-vitro evaluation of the anti-diabetic activity of alcoholic extracts of certain plants belonging to families meliaceae and fabaceae. Nat Prod Indian J. 2014;10 https://www.tsijournals.com/abstract/ invitro-evaluation-of-the-antidiabetic-activity-of-alcoholic-extracts-of-certain-pla nts-belonging-to-families-meliaceae\%2D\%2D5206.html. Accessed 11 July 2020.

12. Seif MM, Ahmed-Farid OA-H, Aboulthana WM. Evaluation of the Protective Effect of Acacia senegal Extract against di-(2-ethylhexyl phthalate) Induced Hepato-and Neurotoxicity in Rats. Annu Res Rev Biol. 2017;19:1-17.

13. Alsadeg A, Koko WE, Osman E, Kabbashi A, Dahab M, Garbi M, et al. In Vitro Anthelminthic activity of the methanol stem bark extract of Acacia senegal against Fasciola gigantica. Int Invent J Biochem Bioinformatics. 2015;3:2408722.

14. Mudi SY, Salisu A. Studies on brine shrimp lethality and activity of stem bark extract of Acacia senegal L. on respiratory tract pathogenic bacteria. Int J Biomed Hlth Sci Vol. 2009:5:139-43.

15. Okoro SO, Kawo AH, Arzai AH. Phytochemical Screening, Antibacterial and Toxicological Activities of Acacia Senegal Extracts. Bayero J Pure Appl Sci. 2012;5:163-70

16. Magnini RD, Hilou A, Millogo-Koné H, Pagès J-M, Davin-Regli A. Acacia senegal Extract Rejuvenates the Activity of Phenicols on Selected Enterobacteriaceae Multi Drug Resistant Strains. Antibiotics. 2020;9:323.

17. Ren H, Chen Y, Zhang F, Liu Z, Qi N, Chen Y. Comparative analysis of human mesenchymal stem cells from umbilical cord, dental pulp, and menstrual blood as sources for cell therapy. Stem Cells Int. 2016;2016:13.

18. Mathias F, Kabri Y, Okdah L, Di Giorgio C, Rolain J-M, Spitz C, et al. An Efficient One-Pot Catalyzed Synthesis of 2,4-Disubstituted 5-Nitroimidazoles Displaying Antiparasitic and Antibacterial Activities. Molecules. 2017;22:1278.

19. Olschläger V, Schrader A, Hockertz S. Comparison of primary human fibroblasts and keratinocytes with immortalized cell lines regarding their sensitivity to sodium dodecyl sulfate in a neutral red uptake cytotoxicity assay. Arzneimittelforschung. 2009;59:146-52.

20. Ouedraogo GG, Ouedraogo M, Lamien-Sanou A, Lompo M, GoumbriLompo OM, Guissou PI. Acute and Subchronic Toxicity Studies of Roots Barks Extracts of Calotropis procera (Ait.) R. Br Used in the Treatment of Sickle Cell Disease in Burkina Faso. Br J Pharmacol Toxicol. 2013;4:194-200.

21. Konaté A, Ouedraogo GG, Illboudo S, Ouedraogo N, Kabore A, Traore A, et al. Acute and sub-acute oral toxicity studies of aqueous extract of Securidaca longepedunculata Fresen (Polygalaceae) root barks in rodents. Int J Adv Res. 2016;4:550-8.

22. OECD. Test No. 423: Acute Oral toxicity - Acute Toxic Class Method, OECD Guidelines for the Testing of Chemicals. Section 4. Paris: Éditions OCDE; 2001. https://doi.org/10.1787/9789264071001

23. OECD. Test No. 407: Repeated Dose 28-day Oral Toxicity Study in Rodents, OECD Guidelines for the Testing of Chemicals. Section 4. Paris: Éditions OECD; 2008. https://doi.org/10.1787/9789264070684-en

24. Ilboudo S, Ouedraogo GG, Sawadogo I, Belemnaba L, Ouedraogo S, Nébié RCH. Safety assessment of Cymbopogon shoenanthus (L.) Spreng. (Poaceae) essential oils: Oral toxicity, dermal and eye irritancy investigations. J Toxicol Environ Health Sci. 2019;11:90-9.

25. Stover CK, Pham XQ, Erwin AL, Mizoguchi SD, Warrener P, Hickey MJ, et al. Complete genome sequence of Pseudomonas aeruginosa PAO1, an opportunistic pathogen. Nature. 2000;406:959-64.

26. Vergalli J, Dumont E, Cinquin B, Maigre L, Pajovic J, Bacqué E, et al. Fluoroquinolone structure and translocation flux across bacterial membrane. Sci Rep. 2017;7:9821.

27. Murray TS, Kazmierczak BI. FlhF Is Required for Swimming and Swarming in Pseudomonas aeruginosa. J Bacteriol. 2006;188:6995-7004.

28. Ling $\mathrm{H}$, Kang $\mathrm{A}$, Tan MH, Qi X, Chang MW. The absence of the luxS gene increases swimming motility and flagella synthesis in Escherichia coli K12. Biochem Biophys Res Commun. 2010;401:521-6.

29. Kuete $V$, Efferth T. African flora has the potential to fight multidrug resistance of cancer. Biomed Res Int. 2015;2015 ID 914813:24.

30. Ilboudo S, Some H, Ouedraogo GG, Kini FB, Ouedraogo S, Guissou IP. Phytochemical, acute and subacute toxicity studies of Annona senegalensis Pers. (Annonaceae) root wood extracts. Afr J Biochem Res. 2019;13:44-55. 
31. Teo S, Stirling D, Thomas S, Hoberman A, Kiorpes A, Khetani V. A 90-day oral gavage toxicity study of D-methylphenidate and D. L-methylphenidate in Sprague-Dawley rats Toxicology. 2002;179:183-96.

32. Pfortmueller CA, Uehlinger D, von Haehling S, Schefold JC. Serum chloride levels in critical illness - the hidden story. Intensive Care Med Exp. 2018;6:10.

33. Hassan SW, Ladan MJ, Dogondaji RA, et al. Phytochemical and toxicological studies of aqueous leaves extracts of Erythrophleum africanum. Pak J Biol Sci. 2007:10:3815-21.

34. Rhiouani H, El-Hilaly J, Israili ZH, Lyoussi B. Acute and sub-chronic toxicity of an aqueous extract of the leaves of Herniaria glabra in rodents. J Ethnopharmacol. 2008;118:378-86.

35. Chiang P, Burrows LL. Biofilm formation by hyperpiliated mutants of Pseudomonas aeruginosa. J Bacteriol. 2003;185:2374-8.

36. OToole GA, Kolter R. Flagellar and twitching motility are necessary for Pseudomonas aeruginosa biofilm development. Mol Microbiol. 1998;30:295-304.

37. Ren D, Sims JJ, Wood TK. Inhibition of biofilm formation and swarming of Escherichia coli by (5Z)-4-bromo-5-(bromomethylene)-3-butyl-2(5H)furanone. Environ Microbiol. 2001;3:731-6.

38. Klausen M, Heydorn A, Ragas P, Lambertsen L, Aaes-Jørgensen A, Molin S, et al. Biofilm formation by Pseudomonas aeruginosa wild type, flagella and type IV pili mutants. Mol Microbiol. 2003;48(6):1511-24.

39. Lee J-H, Cho HS, Joo SW, Regmi SC, Kim J-A, Ryu C-M, et al. Diverse plant extracts and trans-resveratrol inhibit biofilm formation and swarming of Escherichia coli O157:H7. Biofouling. 2013;29:1189-203.

40. O'May C, Tufenkji N. The Swarming Motility of Pseudomonas aeruginosa Is Blocked by Cranberry Proanthocyanidins and Other Tannin-Containing Materials ${ }^{7}$. Appl Environ Microbiol. 2011;77:3061-7.

41. Serrano J, Puupponen-Pimiä R, Dauer A, Aura A-M, Saura-Calixto F. Tannins: Current knowledge of food sources, intake, bioavailability and biological effects. Mol Nutr Food Res. 2009;53:S310-29.

42. Ronald A. The etiology of urinary tract infection: traditional and emerging pathogens. Dis--Mon DM. 2003;49:71-82.

43. Beachey EH. Bacterial adherence: adhesin-receptor interactions mediating the attachment of bacteria to mucosal surface. J Infect Dis. 1981;143:325-45.

44. Amy B. Howell. Bioactive compounds in cranberries and their role in prevention of urinary tract infections. Mol Nutr Amp Food Res. 2007;51:732-7.

45. Pratt LA, Kolter R. Genetic analysis of Escherichia coli biofilm formation: roles of flagella, motility, chemotaxis and type I pili. Mol Microbiol. 1998;30:285-93.

46. Beloin C, Roux A, Ghigo JM. Escherichia coli biofilms. Curr Top Microbiol Immunol. 2008;322:249-89.

47. Wood TK. Insights on Escherichia coli biofilm formation and inhibition from whole-transcriptome profiling. Environ Microbiol. 2009;11:1-15.

48. Kilkenny C, Browne WJ, Cuthill IC, Emerson M, Altman DG. Improving Bioscience Research Reporting: The ARRIVE Guidelines for Reporting Animal Research. PLoS Biol. 2010;8:e1000412.

\section{Publisher's Note}

Springer Nature remains neutral with regard to jurisdictional claims in published maps and institutional affiliations.

Ready to submit your research? Choose BMC and benefit from:

- fast, convenient online submission

- thorough peer review by experienced researchers in your field

- rapid publication on acceptance

- support for research data, including large and complex data types

- gold Open Access which fosters wider collaboration and increased citations

- maximum visibility for your research: over $100 \mathrm{M}$ website views per year

At BMC, research is always in progress.

Learn more biomedcentral.com/submissions 